\title{
Beneficial Effect of Brewers' Yeast Extract on Daily Activity in a Murine Model of Chronic Fatigue Syndrome
}

\section{Takashi Takahashi ${ }^{1}$, Fei Yu ${ }^{1}$, Shi-jie Zhu ${ }^{1}$, Junji Moriya ${ }^{1}$, Hiroyuki Sumino ${ }^{4}$, Shigeto Morimoto ${ }^{2}$, Nobuo Yamaguchi ${ }^{3}$ and Tsugiyasu Kanda ${ }^{1}$}

\author{
${ }^{1}$ Department of General Medicine, ${ }^{2}$ Department of Geriatric Medicine and ${ }^{3}$ Department of Serology, \\ Kanazawa Medical University, Ishikawa, Japan and ${ }^{4}$ Department of Medicine and Biological Science, \\ Gunma University Graduate School of Medicine, Gunma, Japan
}

\begin{abstract}
The aim of this study was to assess the effect of Brewers' yeast extract (BYE) on daily activity in a mouse model of chronic fatigue syndrome (CFS). CFS was induced by repeated injection of Brucella abortus (BA) antigen every 2 weeks. BYE was orally administered to mice in a dose of $2 \mathrm{~g}$ per $\mathrm{kg}$ per day for 2 weeks before injecting BA and for 4 weeks thereafter. We evaluated daily running activity in mice receiving BYE as compared with that in untreated mice. Weekly variation of body weight (BW) and survival in both groups was monitored during the observation period. Spleen weight (SW), $\mathrm{SW} / \mathrm{BW}$ ratio, percent splenic follicular area and expression levels of interferon- $\gamma$ (IFN- $\gamma$ ) and interleukin-10 (IL-10) mRNA in spleen were determined in both groups at the time of sacrifice. The daily activity during 2 weeks after the second BA injection was significantly higher in the treated group than in the control. There was no difference in BW between both groups through the experimental course. Two mice in the control died 2 and 7 days after the second injection, whereas no mice in the treated group died. Significantly decreased SW and SW/BW ratio were observed in the treated mice together with elevation of splenic follicular area. There were suppressed IFN- $\gamma$ and IL-10 mRNA levels in spleens from the treated mice. Our results suggest that BYE might have a protective effect on the marked reduction in activity following repeated BA injection via normalization of host immune responses.
\end{abstract}

Keywords: Brewers' yeast extract - chronic fatigue syndrome - daily activity - spleen

\section{Introduction}

Fatigue is a common clinical feature in subjects with various immunologic disorders or infectious diseases (1). However, the pathophysiology of fatigue status is still unclear. Several cytokines produced during the immune response to infection are described to be mediators of some symptoms including fever, somnolence, lymphadenopathy and appetite loss (2). It is suggested that these cytokines also have a role in eliciting such fatigue condition (3).

For reprints and all correspondence: Prof. Tsugiyasu Kanda, Department of General Medicine, Kanazawa Medical University, 1-1 Daigaku, Uchinadamachi, Kahoku-gun, Ishikawa 920-0293, Japan. Tel: +81-76-286-2211 ext. 3841; Fax: +81-76-286-2702; E-mail: kandat@kanazawa-med.ac.jp
Chronic fatigue syndrome (CFS) is an incapacitating illness defined by disabling chronic fatigue and characteristic accompanying signs (4). A reduction in daily activity $>50 \%$ for at least 6 months is a major criterion for diagnosis of CFS (5). Hypotheses about the etiology of CFS propose the involvement of a specific bacterial or viral infection and immune dysfunction associated with the infection. Previous research described an immunologic model of CFS induced by intraperitoneal administration of bacterial antigen; however, the duration of fatigue condition evaluated by wheel running was shown to be short (6). Ottenweller et al. (7) have reported the establishment of a mouse model of CFS which could be induced by Brucella abortus (BA) administration. In this model, the mice were found to diminish their voluntary

(C) The Author (2006). Published by Oxford University Press. All rights reserved.

The online version of this article has been published under an open access model. Users are entitled to use, reproduce, disseminate, or display the open access version of this article for non-commercial purposes provided that: the original authorship is properly and fully attributed; the Journal and Oxford University Press are attributed as the original place of publication with the correct citation details given; if an article is subsequently reproduced or disseminated not in its entirety but only in part or as a derivative work this must be clearly indicated. For commercial re-use, please contact journals.permissions@oxfordjournals.org 
activity in the running wheel after intravenously injecting the fixed killed whole BA ring test antigen (7). The advantage of using this model is that the experiment uses voluntary exertion, and that the ability to run for longer periods characterizes recovery. Thus, the BA-induced mouse model is a good one for studying the biological underpinnings of chronic fatigue. We have recently demonstrated the effectiveness of Hochuekki-to (TJ-41), a Japanese herbal medicine for the daily running activity in the same model of CFS (8). BA administration was also known to induce changes in cytokine expression characterized by elevated interleukin-10 (IL-10) and interferon- $\gamma$ (IFN- $\gamma$ ) in $\mathrm{CD}^{+}{ }^{+} \mathrm{T}$ cells in mice (9).

Beer is a complex alcoholic beverage made from malt, hops, water and Brewers' yeast. Scientific evidence has accumulated over the past 10 years pointing to the cancer preventive potential of selected hops-derived beer constituents, i.e. prenylflavonoids including xanthohumol and isoxanthohumol, and hop bitter acids (10). Generally, a strain of Brewers' yeast such as Saccharomyces pastorianus or Saccharomyces cerevisiae is applied as yeast for beer fermentation, and after brewing, a part of the yeast is recovered from the brewing instrument and used for additional yeast products including the Brewers' yeast extract (BYE) as well as the dried yeast. This extract has been widely used as a food ingredient and a seasoning. Although BYE includes many soluble components of vitamin B group, amino acids, peptides and mineral materials, nutritional or pharmacological aspects of BYE have yet to be fully understood. Since the vitamins and microelements are frequently utilized for the prevention and therapy for CFS, BYE is a candidate of the nutritional supplement for CFS.

Puri et al. (11) have reported eicosapentaenoic acid-rich essential fatty acid supplementation in CFS associated with symptom remission and structural brain changes. We describe the effect of BYE on daily running activity in a murine model of CFS. In addition, the differences in pathological modification and cytokine gene expression in spleen between BYEtreated mice and control are determined.

\section{Materials and Methods}

\section{Living Conditions}

Female BALB/c mice, 8 weeks of age, were obtained from Charles River (Kanagawa, Japan), and housed singly in cages $(230 \times 100 \times 100 \mathrm{~mm})$ including running wheels $(230 \mathrm{~mm}$ in diameter), counters showing running wheel activity and water taps, which were obtained from Natsume Seisakusho Co., Ltd (Tokyo, Japan). These cages were maintained under a lightdark photoperiod (10 h versus $14 \mathrm{~h}$ ) provided by fluorescent bulbs fitted in the cage floor. We fed all the mice $(n=20)$ every day during the course of the experiment. Environmental air temperature was maintained at $24-25^{\circ} \mathrm{C}$. The daily running activity of mice was defined as the number of wheel complete turns per $24 \mathrm{~h}$. The running activity was measured at 9 o'clock when the environmental lighting was turned on. Approval for this experiment was obtained from the animal experiment committee in Kanazawa Medical University.

\section{Induction of CFS by BA}

Fixed killed whole BA ring test antigen (BA strain 1119-3, lot no. 302) was obtained from the National Veterinary Services Laboratories in the United States Department of Agriculture. CFS was induced by two repeated injections of original BA antigen solution $(0.2 \mathrm{ml}$ per mouse) via the tail vein every 2 weeks (8). In the pilot experiment, we had already confirmed that the mice with a single administration of BA showed less running activity for 2-3 weeks after injection and recovery from the reduced activity thereafter (8). The criteria for establishing induction of CFS were statistically significant decreases of the running activity after first or second BA injection as compared with the baseline levels.

\section{Treatment of Mice with Brewers' Yeast Extract}

We obtained BYE (lot no. 909031) from Asahi Breweries, Ltd (Tokyo, Japan). The components in BYE are shown in Table 1. This agent was dissolved in distilled water and diluted with water to the appropriate concentration. The BYE solution was administered orally in a dose of $2 \mathrm{~g}$ per $\mathrm{kg}$ once daily through a feeding cannula inserted down the throat of the

Table 1. Components of brewing yeast extract used in the study

\begin{tabular}{lc}
\hline Components & Amount (per $100 \mathrm{~g}$ extract) \\
\hline${\text { Vitamin } \mathrm{B}_{1}}$ & $13.11 \mathrm{mg}$ \\
${\text { Vitamin } \mathrm{B}_{2}}$ & $5.10 \mathrm{mg}$ \\
Vitamin $_{6}$ & $4.73 \mathrm{mg}$ \\
Pantothenate & $4.48 \mathrm{mg}$ \\
Zinc & $6.76 \mathrm{mg}$ \\
Glutathione & $180 \mathrm{mg}$ \\
Arginine & $4.66 \mathrm{~g}$ \\
Lysine & $5.36 \mathrm{~g}$ \\
Histidine & $1.65 \mathrm{~g}$ \\
Phenylalanine & $2.60 \mathrm{~g}$ \\
Tyrosine & $0.83 \mathrm{~g}$ \\
Leucine & $3.95 \mathrm{~g}$ \\
Isoleucine & $3.06 \mathrm{~g}$ \\
Methionine & $1.03 \mathrm{~g}$ \\
Valine & $3.89 \mathrm{~g}$ \\
Alanine & $4.55 \mathrm{~g}$ \\
Glycine & $3.25 \mathrm{~g}$ \\
Proline & $2.42 \mathrm{~g}$ \\
Glutamic acid & $7.44 \mathrm{~g}$ \\
Serine & $3.12 \mathrm{~g}$ \\
Threonine & $3.07 \mathrm{~g}$ \\
Asparaginic acid & $6.90 \mathrm{~g}$ \\
Tryptophan & $0.87 \mathrm{~g}$ \\
Cystine & $0.58 \mathrm{~g}$ \\
\hline
\end{tabular}


mice $(n=10)$ for 2 week before the induction of CFS and for 4 weeks thereafter. The dose of the BYE was determined on the basis of findings of another research applying the same BYE for the fatigue mice (12). Untreated mice $(n=10)$ were given saline during the same period. The mice in this experiment were randomly assigned to the BYE-treated or the control group.

\section{Daily Running Activity, Body Weight and Survival in Mice}

We started to examine the running activity during 2 weeks at baseline levels after 2 weeks of housing, since the activity was stabilized after $2-3$ weeks of housing $(7,8)$. Daily activity during 2 weeks after each injection of BA was evaluated in the mice receiving $\mathrm{BYE}$ as compared with that in the untreated mice. We measured body weight (BW) in both groups weekly from the start of treatment with the extract to the end of experiment. Survival in both groups was also monitored during the observation period.

\section{Organ Weights and Pathological Examination in Spleen and Thymus}

The mice in both groups were sacrificed by cervical dislocation 4 weeks after the first BA injection. Ratios of spleen weight $(\mathrm{SW})(\mathrm{mg})$ to $\mathrm{BW}(\mathrm{g})(\mathrm{SW} / \mathrm{BW})$, thymus weight (TW) (mg) to BW (TW/BW), heart weight (HW) (mg) to BW (HW/BW) and lung weight (LW) (mg) to BW (LW/ BW) as well as the weights of the organs and the body were assessed between both groups at the time of sacrifice. One half of spleen and thymus was fixed in $10 \%$ buffered formalin and stained with hematoxylin-eosin; the other half was frozen and stored at $-80^{\circ} \mathrm{C}$ until analysis of cytokine gene expression. We performed measurements of the splenic lymphoid follicular area and thymic medullary area to be expressed as a percentage of total splenic or thymic area in the long-axis sections (13). The splenic follicular area and thymic medullary area were examined in a normal female BALB/c mouse. Each tissue was evaluated blindly by an experienced pathologist who had no knowledge of the study design.

\section{Expression Levels of INF- $\gamma$ and IL-10 mRNA in Spleen}

RNA extraction for each frozen splenic tissue was performed as described by the manufacturer (RNeasy Mini Kit, QIAGEN Inc., Tokyo, Japan). Procedure of DNase was performed during the RNA extraction to avoid DNA contaminations. The total RNA concentrations were determined by measuring the optical density at 260 and $280 \mathrm{~nm}$. Aliquots of $20 \mu \mathrm{l} \mathrm{RNA}$ from each tissue were applied for production of cDNA. Comparative expression levels of IFN- $\gamma$ (proinflammatory cytokine) and IL-10 (anti-inflammatory cytokine) mRNA in spleens from both groups were determined by using real-time quantitative RT-PCR as described previously $(7,8)$. We applied TaqMan MGB Probe (Applied Biosystems Inc., CA, USA) for the RT-PCR. Commercially available kits for
IFN- $\gamma$ and IL-10 RT-PCR (Mm00801778_m1 and Mm00439616_m1, Applied Biosystems Inc.) were used. Each threshold cycle number up to 50 cycles $\left(C_{\mathrm{t}}\right.$ value $)$ within the RT-PCR was examined for the IFN- $\gamma$ and IL-10 mRNA levels. Glyceraldehyde-3-phosphate dehydrogenase (GAPDH) gene was used as an endogenous internal standard, and was amplified with specific primers for the number of cycles. A negative control without template cDNA was always included. $\Delta C_{\mathrm{t}}$ values referred to differences between the $C_{\mathrm{t}}$ values for each target gene and the GAPDH gene. After confirming that efficiencies of amplification of each molecule and GAPDH transcripts were approximately equal, amount of the IFN- $\gamma$ or IL-10 transcript relative to the GAPDH transcript was determined using the comparative $C_{\mathrm{t}}$ method described in Perkin Elmer Applied Biosystems User Bulletin \#2 (1997). Data are expressed as fold-increases relative to the baseline $($ value $=1$ ) in spleen from a normal female BALB/c mouse.

\section{Statistical Analyses}

Data are expressed as mean values \pm SD. Significant changes of the activity after first or second BA injection as compared with the baseline levels were evaluated by the paired Student's $t$-test. Data differences between the mice treated with the yeast extract and the control were analyzed by the unpaired Student's $t$-test. A $P$-value of $<0.05$ was considered to be statistically significant.

\section{Results}

\section{Daily Running Activity, Body Weight and Survival in Mice}

Daily running activity in both mouse groups before and after repeated BA injection is indicated in Fig. 1. Significant decreases of the activity after first or second BA injection as compared with the baseline levels were observed in the treatment and control groups, showing the induction of CFS. The baseline activity and the activity during 2 weeks after the first BA injection were not significantly different between both groups (Fig. 1). However, the activity during 2 weeks after the second BA injection was significantly higher in the group treated with BYE than in the control $(8966+1647$ versus $4821+1355$, respectively, $P<0.05$ ). There was no significant difference in BW between both the groups through the observation course, although a transient decline in BW was found in the control (Fig. 2). Two mice in the untreated group died 2 and 7 days after the second BA injection, whereas no mice in the group treated with BYE died.

\section{Organ Weights and Pathological Examination in Spleen and Thymus}

Ratios of each organ to BW as well as BW, SW, TW, HW and LW in both groups are shown in Table 2. Significant reduction in SW was found in the mice treated with BYE as compared with that in the control $(329 \pm 73 \mathrm{mg}$ versus $517 \pm 98 \mathrm{mg}$, 


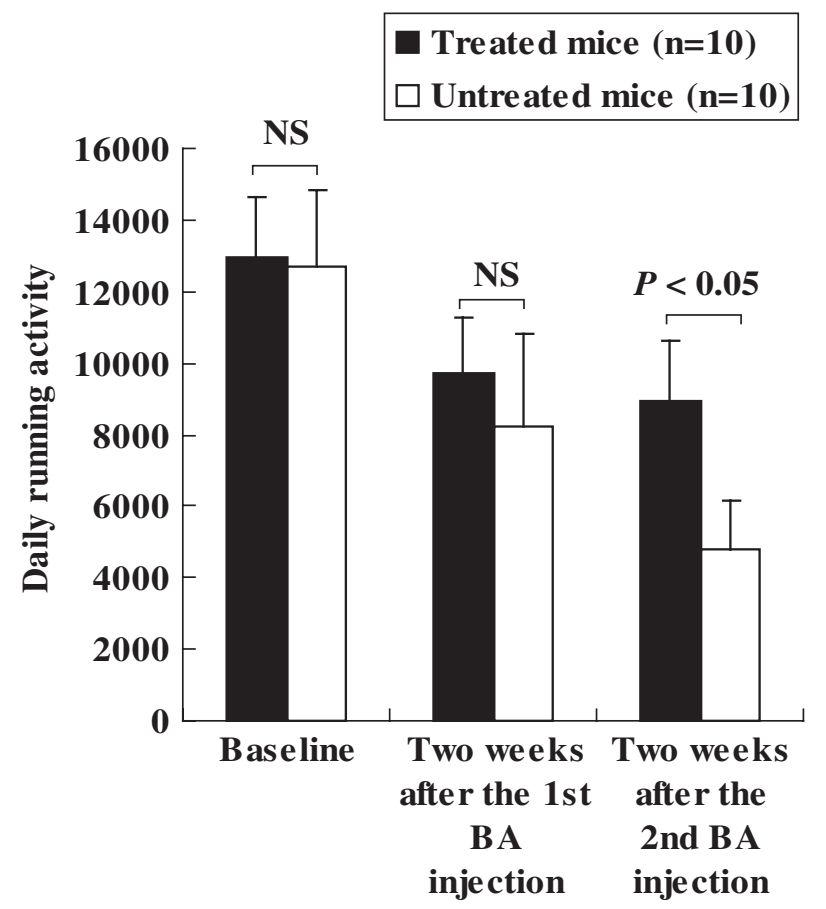

Figure 1. Effect of brewing yeast extract on daily running activity in a mouse model of chronic fatigue syndrome. Data are expressed as means \pm SD. NS, not significant; BA, Brucella abortus. Daily running activity was defined as the number of wheel turns per $24 \mathrm{~h}$. Asterisk represents two mice in the untreated group died 2 and 7 days after the second injection of BA, while no mice in the treated group died.

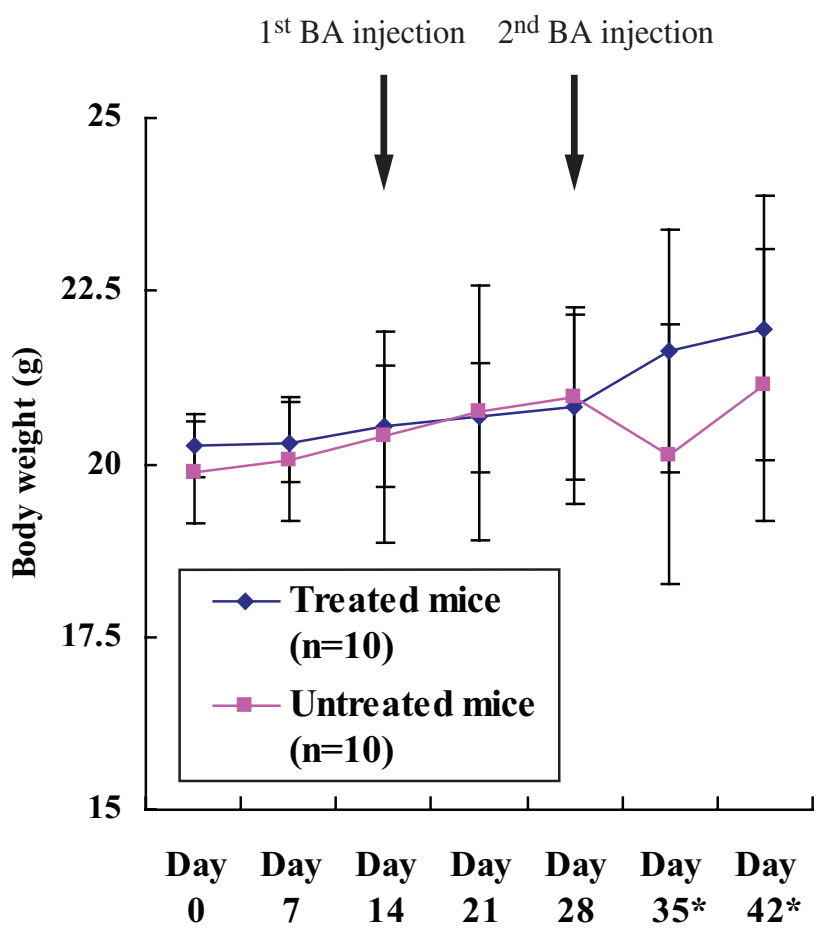

Figure 2. Weekly variation of body weight between different mice from the start of treatment with brewing yeast extract to the end of experiment. Data are expressed as means \pm SD. NS, not significant; BA, Brucella abortus. Asterisk represents two mice in the untreated group died 2 and 7 days after the second injection of BA, while no mice in the treated group died.
Table 2. Effect of brewing yeast extract on body weight and weight of organs including spleen, thymus, heart and lungs at the time of sacrifice

\begin{tabular}{llllll}
\hline & $\begin{array}{l}\mathrm{BW} \\
(\mathrm{g})\end{array}$ & $\begin{array}{l}\mathrm{SW} \\
(\mathrm{mg})\end{array}$ & $\begin{array}{l}\mathrm{TW} \\
(\mathrm{mg})\end{array}$ & $\begin{array}{l}\mathrm{HW} \\
(\mathrm{mg})\end{array}$ & $\begin{array}{l}\mathrm{LW} \\
(\mathrm{mg})\end{array}$ \\
\hline Treated mice & $22.0 \pm 1.9$ & $329 \pm 73^{*}$ & $44 \pm 7$ & $114 \pm 15$ & $158 \pm 22$ \\
$(n=10)$ & & $\left(15.0 \pm 3.4^{*}\right)$ & $(2.1 \pm 0.2)$ & $(5.2 \pm 0.7)$ & $(7.2 \pm 1.0)$ \\
Untreated mice & $21.2 \pm 2.0$ & $517 \pm 98$ & $42 \pm 4$ & $111 \pm 10$ & $152 \pm 20$ \\
$(n=8)^{* *}$ & & $(24.5 \pm 4.7)$ & $(2.0 \pm 0.2)$ & $(5.1 \pm 0.5)$ & $(7.1 \pm 0.9)$ \\
\hline
\end{tabular}

Data are expressed as means \pm SD. BW, body weight; SW, spleen weight; TW, thymus weight; HW, heart weight; LW, lungs weight. Parentheses show ratio of each organ weight to body weight.

$* P<0.05$ compared with spleen weight in the untreated mice.

**Two mice in the untreated group died 2 and 7 days after the second injection of BA.

respectively, $P<0.05$ ), whereas there were no differences in the weights of other organs between both the groups (Table 2). SW/BW ratio was significantly lower in the group treated with BYE than in the untreated group at the time of sacrifice $(15.0 \pm 3.4$ versus $24.5 \pm 4.7, P<0.05)$, while TW/BW, HW/BW and LW/BW ratios were not significantly different between both the groups (Table 2). The percent follicular area and medullary area were 31 and $28 \%$ in spleen and thymus of the normal female BALB/c mouse. Significantly, increase of splenic follicular area was observed in the treated mice as compared with that in the untreated group (24 $\pm 8 \%$ versus $14 \pm 6 \%$, respectively, $P<0.05$ ). As shown in Fig. 3B, the lymphoid follicles were found to be impaired in spleens of the untreated mice. However, there was no difference in thymic medullary area between both the groups (Fig. 3A).

\section{Expression Levels of IFN- $\gamma$ and IL-10 mRNA in Spleen}

Comparative expression levels of IFN- $\gamma$ and IL-10 mRNA in spleen are shown in Fig. 4A and B. The IFN- $\gamma$ and IL-10 mRNA levels in spleens of the mice treated with BYE were significantly lower than those in the control $(7.67 \pm 5.97$ versus $13.87 \pm 4.77$ and $5.18 \pm 1.36$ versus $8.45 \pm 1.94$ in IFN- $\gamma$ and IL-10 mRNA levels, respectively, $P<0.05)$.

\section{Discussion}

Vitamins and microelements such as high amounts of vitamins $\mathrm{B}, \mathrm{K}$ and essential amino acids are very important for the prevention and treatment for individuals with fatigue. In a clinical study, a nutritional supplement 'Nagipol' made on the basis of Brewers' yeast in Russia was applied for the prevention and treatment of CFS patients (14). The results showed that this food was useful in CFS because of the clinical status improvement, positively influencing cognitive CNS functions and symptoms of emotional instability and normalizing blood biochemical parameters, suggesting recommendation of the food as preventive medical dietetic means for this pathology. We have also found the beneficial effect of BYE on daily running activity in a murine model of CFS. It might be worth 

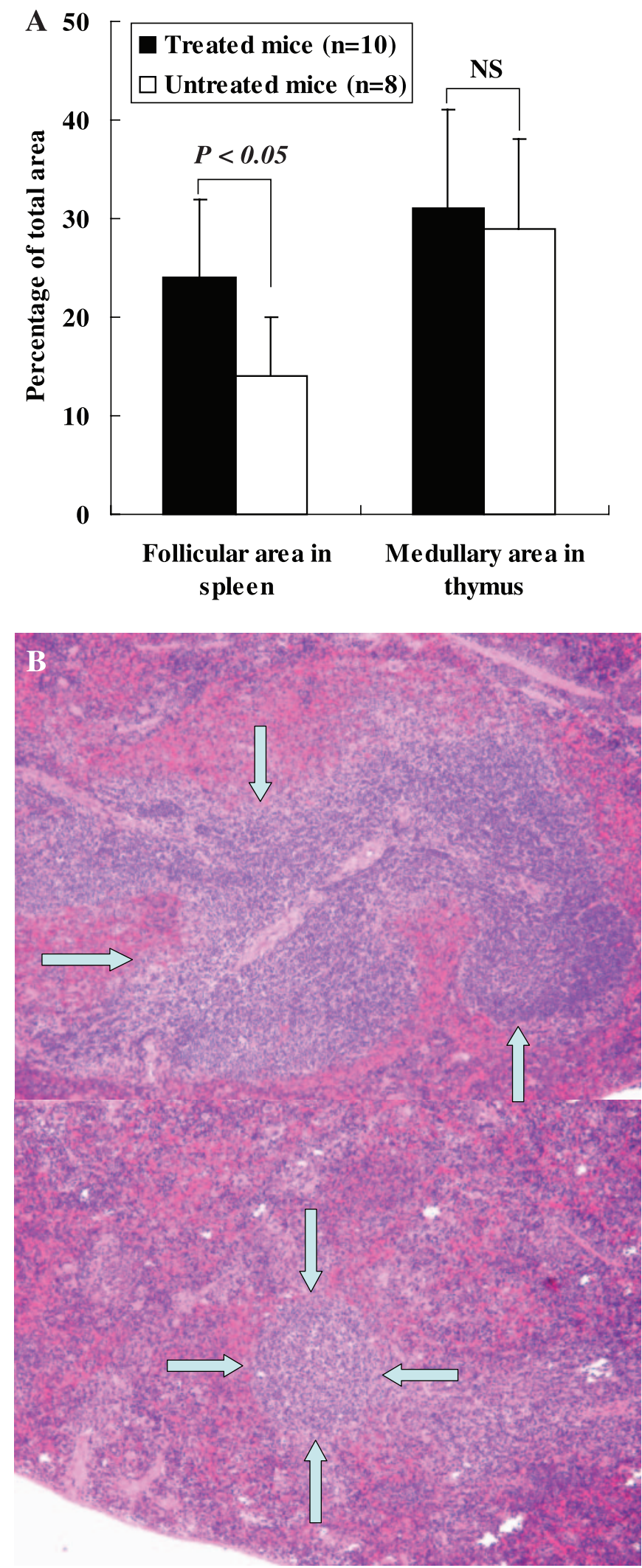

Figure 3. Percentages of splenic lymphoid follicular area and thymic medullary area between different mice (A) and pathological findings of the follicular area in spleen (B, upper image in the treated mice and lower image in the control). Data are expressed as means \pm SD. NS, not significant; BA, Brucella abortus. Arrows show the follicular area in the spleen.
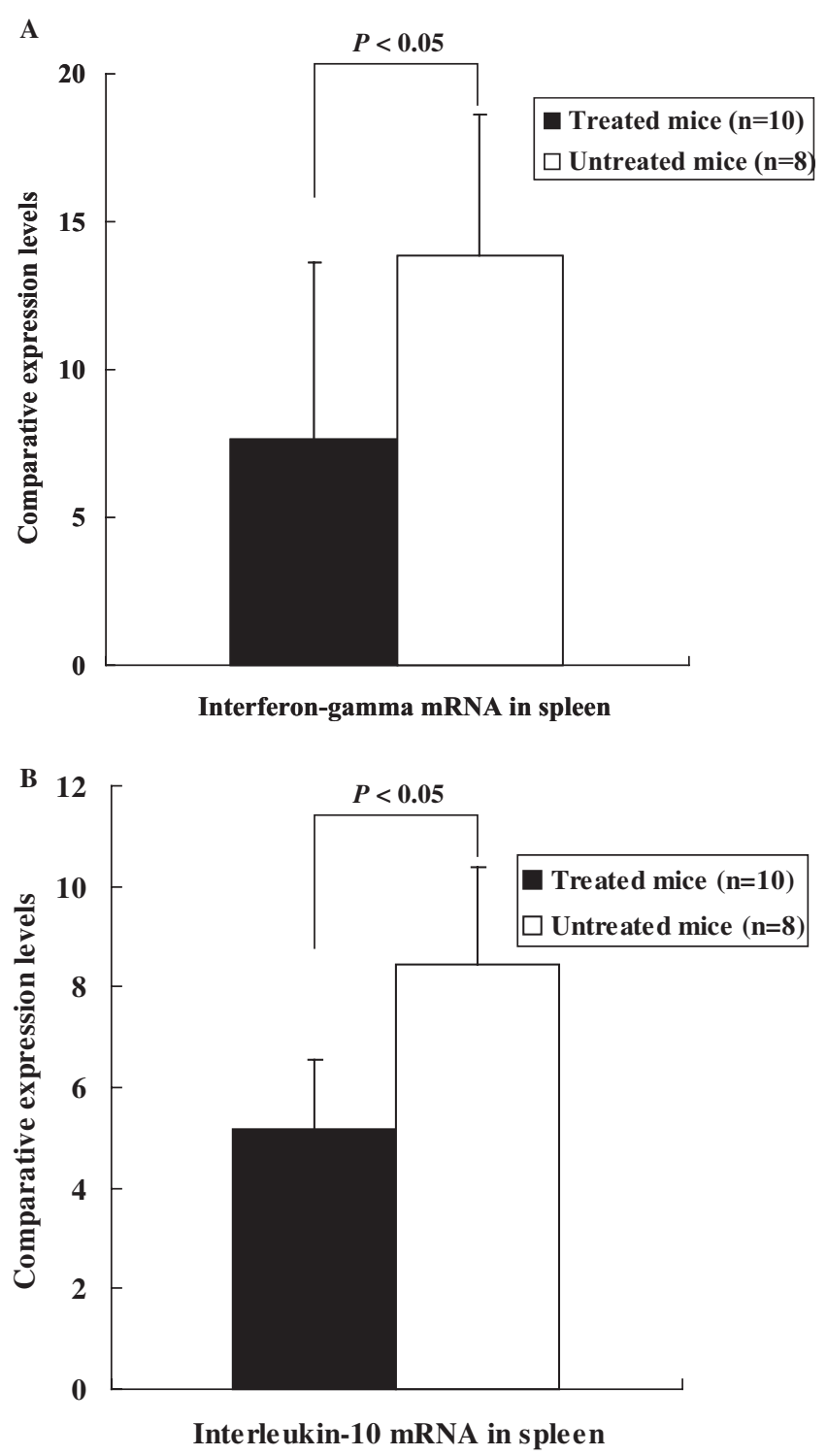

Figure 4. Comparative expression levels of interferon- $\gamma$ (INF- $\gamma)(\mathbf{A})$ and interleukin-10 (B) mRNA in spleen between different mice. Data are expressed as means \pm SD. The INF- $\gamma$ and interleukin- 10 mRNA levels were calculated as comparative values, which were normalized to the cytokines' mRNA in the spleen from normal female BALB/c mouse (value $=1$ ).

investigating the effectiveness of BYE on symptoms in the CFS or fatigue subjects with other various disorders in future clinical study.

Previous study reported clinical aspects of 21 individuals with chronic brucellosis (15). Seventeen patients suffered from chronic disease and had no history of any acute episode of brucellosis. The most common symptoms in the patient population were tiredness, fatigue, depression, arthralgia and muscular pains. Most of these subjects had already been receiving psychiatric treatment. Clinical examination was largely negative, but lymphadenopathy was found in nine cases. Based on these clinical manifestations, the fatigue induced by BA administration which was used in the present research might be applicable to a mouse model of CFS. 
There are manuscripts regarding splenomegaly induced by brucellosis $(16,17)$. Inhibition of in vitro lymphocyte proliferation by brucella-activated macrophages was also found during experimental murine brucellosis (18). Increase of SW and SW/ $\mathrm{BW}$ ratio after the repeated $\mathrm{BA}$ injection was observed together with decrease of splenic follicular area in the present study, and there was significant improvement of SW, SW/BW ratio and splenic follicular area in the treated group, suggesting that the measurement of splenic enlargement and follicular area might be useful to monitor improvement of immune stimulation during treatment.

We found significant decreases of IFN- $\gamma$ (proinflammatory cytokine) and IL-10 (anti-inflammatory cytokine) mRNA levels in the spleens of the mice treated with BYE as compared with those of the control. Svetic et al. (9) described that simultaneous elevation in Th 1 cytokine, IFN- $\gamma$, and Th 2 cytokine, IL-10, appeared in type 1 immune responses after the BA injection. Reduced expression of IL-2 and -4 as well as increased expression of IL-10 were found in another study using BA (7). Although it is uncertain whether IL-10 plays a role in suppressing severity of inflammatory response mediated by IFN- $\gamma$, BYE treatment could contribute to normalization of host immune responses in the CFS mouse model, suggesting that these cytokines' expression might be a biomarker in the treatment for CFS.

There are few investigations showing the effectiveness of alternative and complementary approaches including nutritional supplements for subjects with CFS. Cox et al. (19) reported that magnesium treatment might improve the well-being of the CFS patients because of low red blood cell magnesium in CFS. In a placebo-controlled study, there were no significant differences in symptoms between the group treated with red-cell membrane essential fatty acids and placebo in CFS (20). In addition, no significant difference was apparent between response to placebo and that to liver extract containing folic acid and cyanocobalamin (21). In our study, daily running activity during 2 weeks after the second BA injection was significantly higher in the group treated with BYE in a dose of $2 \mathrm{~g}$ per $\mathrm{kg}$ per day than in the control. Significantly lowered SW and SW/BW ratio was observed in the treated mice together with increase of splenic follicular area. There were decreased IFN- $\gamma$ and IL-10 mRNA levels in spleens of the treated group. These data suggest that BYE treatment might possess a preventive effect on the marked reduction in running activity following the repeated BA injection via normalization of host immune responses, although the optimum dose and the appropriate time of initiating the treatment with BYE have not been established in this study. Further investigations are required to elucidate these ancesus. L-arginine increases nitric oxide (NO) release into circulation via endothelial NO synthase. NO suppresses the activation of the key gene of inflammation, nuclear factor kappa B (22), and might account for the beneficial effect of BYE. Therefore, we should consider administering L-arginine alone in a future study.

\section{Acknowledgements}

The authors thank Dr Masaaki Yasue (Fundamental Research Laboratory, Asahi Breweries, Ltd, Ibaraki, Japan) for his helpful suggestions. This study was supported in part by a grant for promoted research from Kanazawa Medical University (S2004-2 and S2005-5), a grant for project research from the High-Technology Center of Kanazawa Medical University (H2004-7) and a research grant from Grant-in-Aid for Scientific Research (C), the Ministry of Education, Science and Culture of Japan (No. 17590767).

\section{References}

1. Krupp LB, LaRocca NG, Muir-Nash J, Steinberg AD. The fatigue severity scale. Application to patients with multiple sclerosis and systemic lupus erythematosus. Arch Neurol 1989;46:1121-3.

2. Tracey KJ, Vlassara H, Cerami A. Cachectin/tumour necrosis factor. Lancet 1989;1:1122-6.

3. Chao CC, Strgar F, Tsang M, Peterson PK. Effects of swimming exercise on the pathogenesis of acute murine Toxoplasma gondii Me49 infection. Clin Immunol Immunopathol 1992;62:220-6.

4. Fukuda K, Straus SE, Hickie I, Sharpe MC, Dobbins JG, Komaroff A. The chronic fatigue syndrome: a comprehensive approach to its definition and study. International Chronic Fatigue Syndrome Study Group. Ann Intern Med 1994;121:953-9.

5. Holmes GP, Kaplan JE, Gantz NM, Komaroff AL, Schonberger LB, Straus SE, et al. Chronic fatigue syndrome: a working case definition. Ann Intern Med 1988;108:387-9.

6. Chao CC, DeLaHunt M, He S, Close K, Peterson PK. Immunologically mediated fatigue: A murine model. Clin Immunol Immunopathol 1992;64:161-5.

7. Ottenweller JE, Natelson BH, Gause WC, Carroll KK, Beldowicz D, Zhou XD, et al. Mouse running activity is lowered by Brucella abortus treatment: a potential model to study chronic fatigue. Physiol Behav 1998;63:795-801.

8. Wang XQ, Takahashi T, Zhu SJ, Moriya J, Saegusa S, Yamakawa J, et al. Effect of Hochu-ekki-to (TJ-41), a Japanese herbal medicine, on daily activity in a murine model of chronic fatigue syndrome. Evid Based Complement Alternat Med 2004;1:203-6.

9. Svetic A, Jian YC, Lu P, Finkelman FD, Gause WC. Brucella abortus induces a novel cytokine gene expression characterized by elevated IL-10 and IFN- $\gamma$ in CD4+ T cells. Int Immunol 1993;5:877-83.

10. Gerhauser C. Beer constituents as potential cancer chemopreventive agents. Eur J Cancer 2005;41:1941-54.

11. Puri BK, Holmes J, Hamilton G. Eicosapentaenoic acid-rich essential fatty acid supplementation in chronic fatigue syndrome associated with symptom remission and structural brain changes. Int J Clin Pract 2004;58:297-9.

12. Nakagawasai O, Tadano T, Yasue M. Effect of brewers yeast extract on a physical fatigue-induced stress in mice. Presentation abstracts of the 58th annual scientific meeting: the Japanese Society of Nutrition and Food Science 2004,265.

13. Kanda T, McManus JEW, Nagai R, Imai S, Suzuki T, Yang DC, et al. Modification of viral myocarditis in mice by interleukin-6. Circ Res 1996;78:848-56.

14. Dotsenko VA, Mosiichuk LV, Paramonov AE. Biologically active food additives for correction of the chronic fatigue syndrome. Vopr Pitan 2004; 73:17-21.

15. Sacks N, Van Rensburg AJ. Clinical aspects of chronic brucellosis. S Afr Med J 1976;50:725-8.

16. Oth D, Sabolovic D, Le Garrec Y. Genetic (h-2) dependence of the duration of splenomegaly induced by Brucella abortus. Folia Biol (Praha) 1974;20:20-5.

17. Demetropoulos KC, Lindenauer SM, Rapp R, Robins J. Target calcifications of the spleen in chronic brucellosis (Brucella suis). J Can Assoc Radiol 1974;25:161-3. 
18. Riglar C, Cheers C. Macrophage activation during experimental murine brucellosis. II. Inhibition of in vitro lymphocyte proliferation by brucella-activated macrophages. Cell Immunol 1980;49:154-67.

19. Cox IM, Campbell MJ, Dowson D. Red blood cell magnesium and chronic fatigue syndrome. Lancet 1991;337:757-60.

20. Warren G, McKendrick M, Peet M. The role of essential fatty acids in chronic fatigue syndrome. A case-controlled study of red-cell membrane essential fatty acids (EFA) and a placebo-controlled treatment study with high dose of EFA. Acta Neurol Scand 1999; 99:112-6.
21. Kaslow JE, Rucker L, Onishi R. Liver extract-folic acidcyanocobalamin vs placebo for chronic fatigue syndrome. Arch Intern Med 1989;149:2501-3.

22. Grumbach IM, Chen W, Mertens SA, Harrison DG. A negative feedback mechanism involving nitric oxide and nuclear factor kappa-B modulates endothelial nitric oxide synthase transcription. $\mathrm{J} \mathrm{Mol} \mathrm{Cell} \mathrm{Cardiol}$ 2005;39:595-603.

Received September 10, 2005; accepted December 25, 2005 


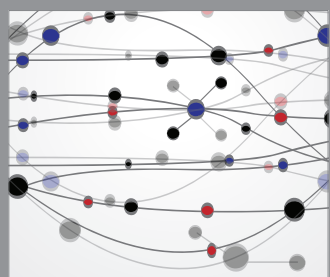

The Scientific World Journal
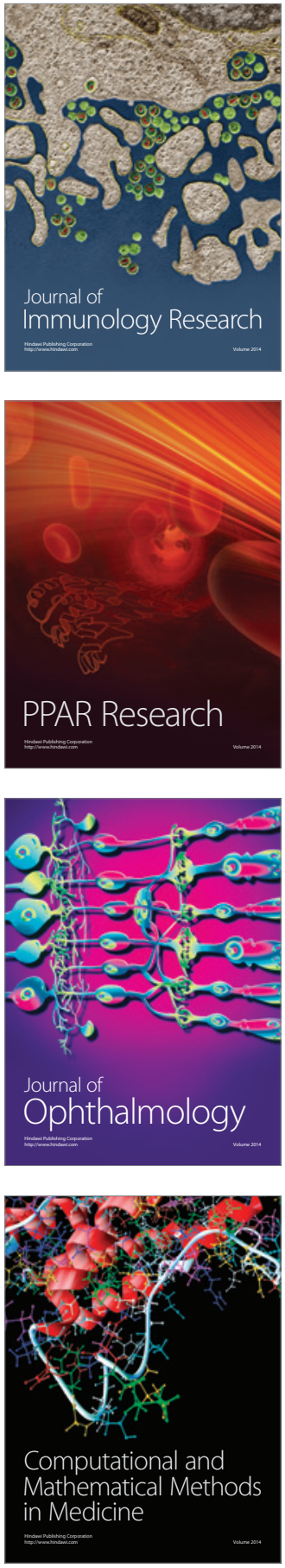

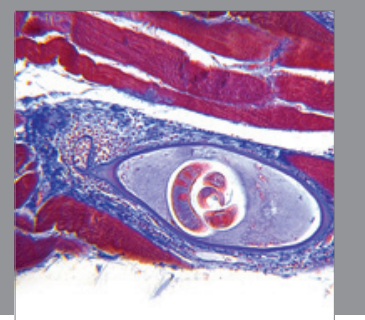

Gastroenterology

Research and Practice
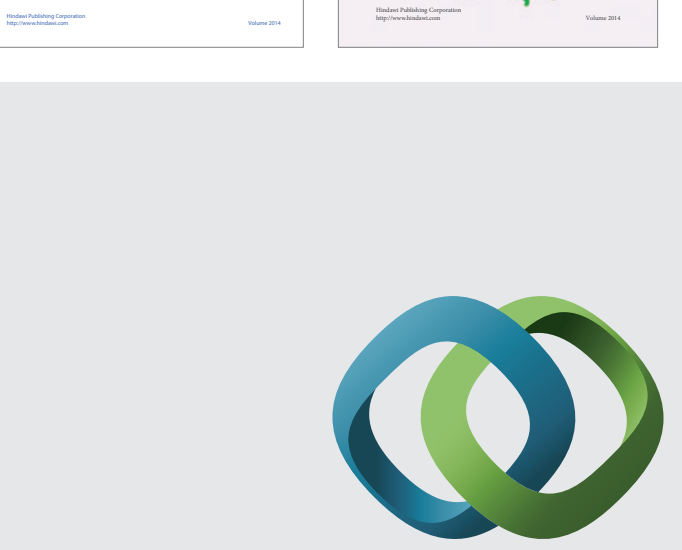

\section{Hindawi}

Submit your manuscripts at

http://www.hindawi.com
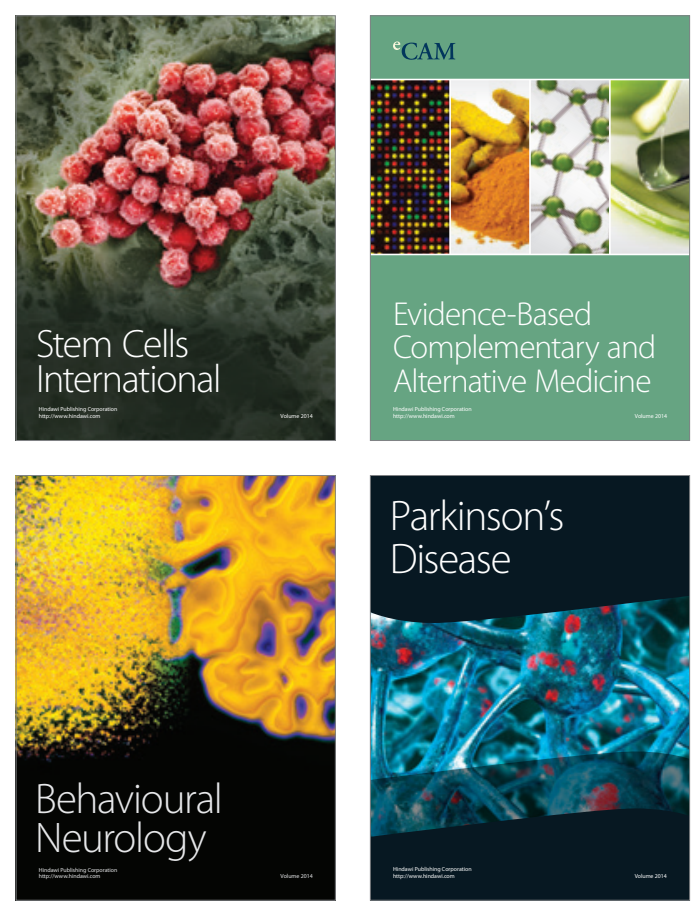

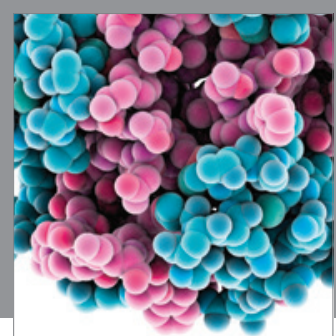

Journal of
Diabetes Research

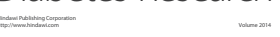

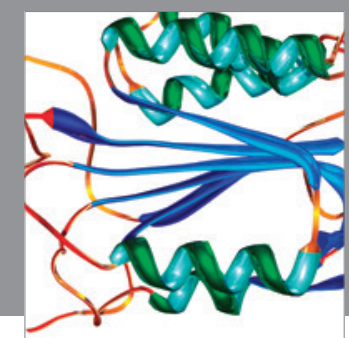

Disease Markers
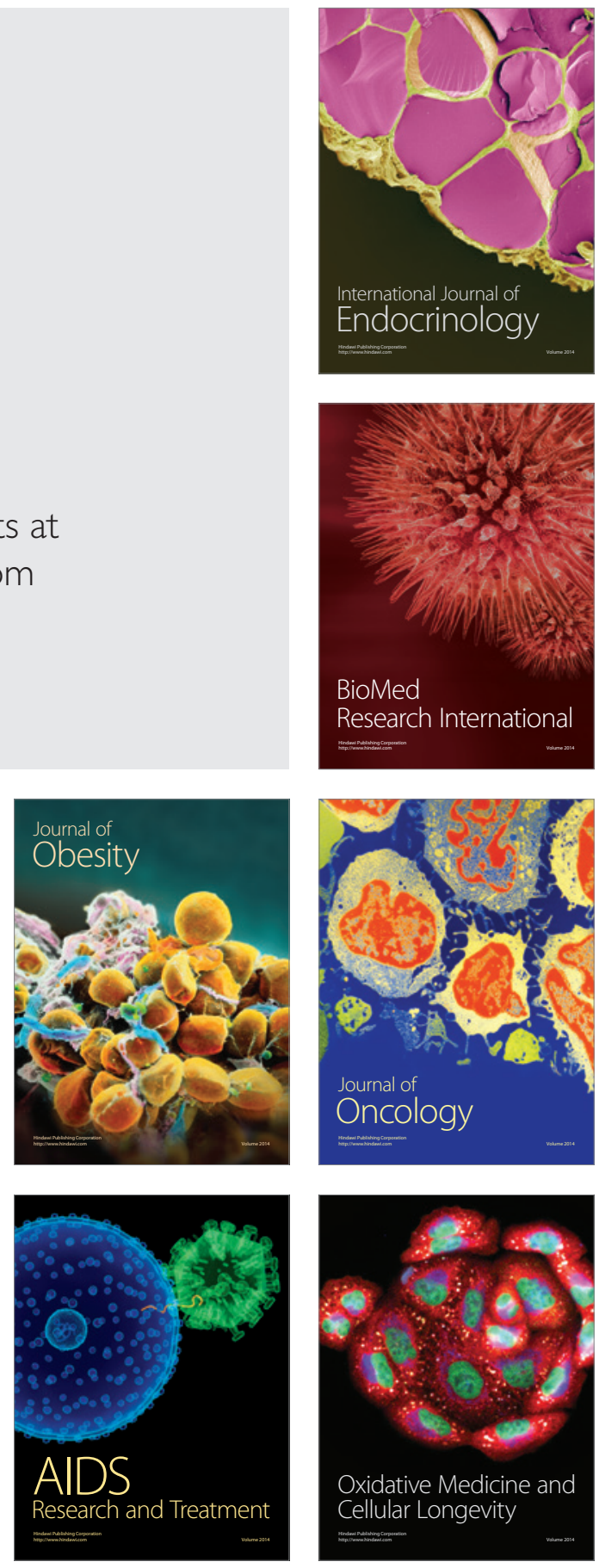